\title{
Paracoccidioidomicose sistêmica multifocal - desafio diagnóstico por manifestação cutânea tardia
}

\author{
Multifocal paracoccidioidomycosis: a diagnostic challenge due to late
}

\author{
cutaneous manifestation
}

\author{
Priscilla Maria Rodrigues Pereira ${ }^{1}$ \\ Patrícia Bandeira de Melo Akel ${ }^{2}$ \\ Livia Lima de Lima ${ }_{5}^{3}$ \\ Alex Panizza Jalkh \\ Eduardo Nobuo Kimura ${ }^{4}$
}

Resumo: No Brasil, a paracoccidioidomicose é uma micose sistêmica endêmica frequente na zona rural e em homens adultos. É relatado caso em agricultor, usuário de drogas ilícitas, com manifestações insidiosas, atingindo rins, pulmões, gânglios, ossos e tardiamente pele, com atraso no diagnóstico e na terapêutica eficaz em mais de um ano. É importante incluir a paracoccidioidomicose como diagnóstico diferencial frente a um quadro sugestivo, mesmo na ausência de lesões cutâneas, para reconhecimento e tratamento precoce, em vista da elevada morbimortalidade desta entidade

Palavras-chave: Diagnóstico; Manifestações cutâneas; Paracoccidioidomicose

\begin{abstract}
Paracoccidioidomycosis is an endemic systemic mycosis in Brazil, frequent in the rural areas and often in adult men. It is reported the case of a farmer, who is an illicit drugs' user, with insidious manifestations affecting kidneys, lungs, lymphonodes, bones and lately, the skin, with a delay of more than one year in the diagnosis and effective therapy It is important to include paracoccidioidomycosis as differential diagnosis, even in the absence of cutaneous lesions, for early recognition and treatment, given the high mortality of this entity.

Keywords: Diagnosis; Paracoccidioidomycosis; Skin manifestations
\end{abstract}

\section{INTRODUÇÃO}

A Paracoccidioidomicose (ou blastomicose sulamericana, ou micose de Lutz Splendore e Almeida) é micose sistêmica de alta prevalência no Brasil, autóctone do continente americano, causada pelo Paracoccidioides brasiliensis, um fungo dimórfico. ${ }^{1,2,3}$ Foi originalmente descrita por Adolfo Lutz, no Brasil, em 1908. ${ }^{2,3}$ É endêmica no Brasil, predominando no sul, sudeste e centro-oeste. ${ }^{3,4} \mathrm{~A}$ fonte de infecção principal é inalatória e o complexo pulmonar pode ser eliminado, tornando-se foco quiescente ou progredindo para órgãos internos. ${ }^{1,5} \mathrm{Na}$ maioria dos casos (70$80 \%$ ), a paracoccidioidomicose (PCM) é multifocal. ${ }^{2}$

\section{RELATO DO CASO}

Paciente masculino, 28 anos, agricultor, natural e procedente de Santarém-Pará. Há 2 anos, apresentou febre alta, linfadenopatia axilar e cervical, perda ponderal, tosse seca, lombalgia e adinamia. Possui história pregressa de alcoolismo, tabagismo e usuário crônico de cocaína. Apresentava proteinúria nefrítica e derrame pleural à direita. Após investigação clínica exaustiva negativa, foi introduzido o esquema empírico para Tuberculose ganglionar. Após 6 meses, mesmo em tratamento regular para tuberculose, retorna com manutenção do quadro anterior e com micro e poliadenopatia generalizadas, além de nódulos eritematosos no dorso

\footnotetext{
Recebido em 16.09.2009.

Aprovado pelo Conselho Consultivo e aceito para publicação em 07.12.2009.

* Trabalho realizado na Universidade Federal do Amazonas (UFAM) - Manaus (AM) - Brasil.

Conflito de interesse: Nenhum / Conflict of interest: None

Suporte financeiro: Nenhum / Financial funding: None
}

\footnotetext{
Médica Residente em Dermatologia pela Universidade Federal do Amazonas (UFAM) - Manaus (AM), Brasil.

Mestre em Patologia Tropical pela Universidade Federal do Amazonas (UFAM). Professora Credenciada de Dermatologia da UFAM. Preceptora da Residência Médica em Dermatologia do Hospital Universitário Getúlio Vargas (HUGV) - Manaus (AM), Brasil.

Médica Residente em Dermatologia da Fundação Alfredo da Matta (FUAM) - Manaus (AM), Brasil.

Médico Dermatologista pela Universidade Federal do Amazonas (UFAM) - Manaus (AM), Brasil.

Médico Dermatologista pela Universidade Federal do Amazonas (UFAM). Professor Voluntário da Universidade Federal do Amazonas (UFAM) - Manaus (AM), Brasil 
do tórax, abdome e pescoço, dor pleurítica, hepatomegalia e ascite. Durante internação, realizou tomografia do tórax que evidenciou derrame pleural direito, lesões hipodensas e lesões osteolíticas no esterno e arco costal direito (Figura 1). Suspeitou-se de sarcoidose e suspenderam-se as medicações para tuberculose. Evoluiu com agudização do quadro dermatológico e novas lesões nódulotumorais, com sinais de flogose e supuração (Figura 2 e 3). Então, foi solicitada a avaliação dermatológica. A primeira biópsia de pele resultou em dermatite crônica granulomatosa, subepidérmica, inespecífica, com ausência de bacilos-álcool-ácido-resistentes e negativa para fungos à coloração Grocott. Praticada nova biopsia cutânea e swab de exsudato do gânglio. No exame direto deste, presença de células arredondadas, birrefringentes, com brotamentos múltiplos compatíveis com Paracoccidioides brasiliensis (Figura 4), confirmado pela cultura. A histopatologia revelou granulomas com células leveduriformes fúngicas, com parede de dupla membrana em gemulação múltipla, esta melhor visualizada quando corada pela prata. Instituiu-se Anfotericina B, com melhora clínica após dose cumulativa de $1 \mathrm{~g}$ (Figura 5). Após 2 meses,recebeu alta hospitalar, com sulfametoxazol e trimetoprima para manutenção, em seguimento dermatológico e pneumológico regularmente, sem novas lesões há um ano.

\section{DISCUSSÃO}

A PCM ocorre, sobretudo em homens (9-13:1), de 30-60 anos, no meio rural, sendo rara em crianças e adultos jovens. ${ }^{2,5}$ Apresenta evolução aguda, subaguda ou crônica, a qual pode acometer um (unifocal) ou mais órgãos (multifocal) ${ }^{5,6}$ No presente caso, a profissão, procedência e o fato da cronicidade do quadro são aspectos relevantes na suspeita clínica desta micose. Porém, o acometimento sistêmico apresentou-se

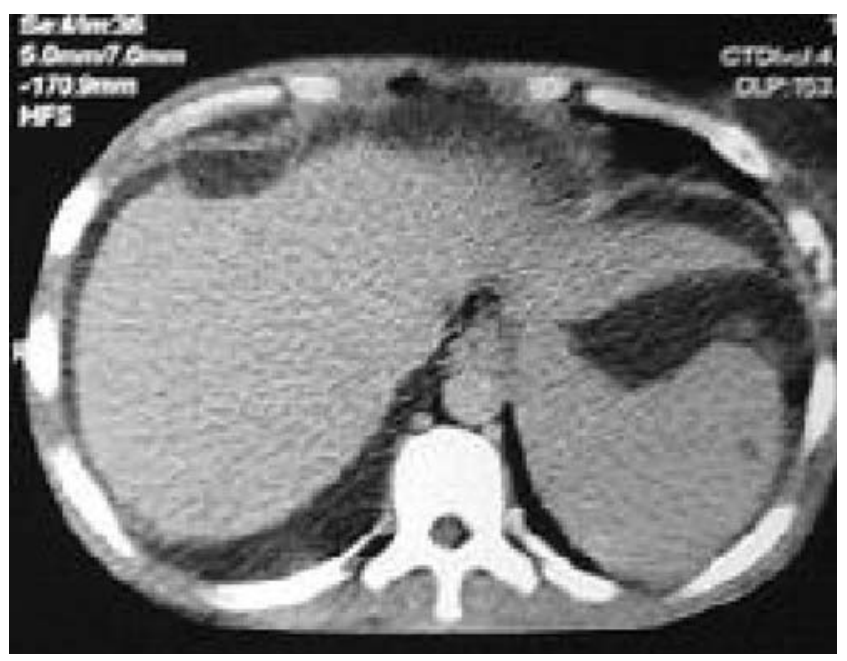

Figura 1: Tomografia de Tórax:Derrame pleural à direita, osteólise do esterno e dos arcos costais à esquerda

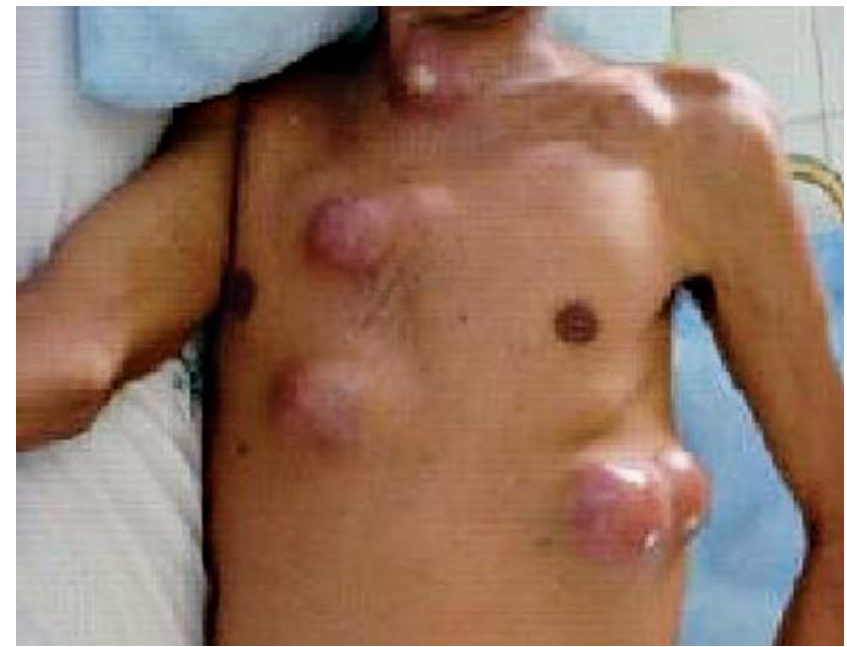

Figura 2: Nódulos recobertos por pele normal, aderidos, firmes no pescoço;face anterior do tórax

de forma lenta e gradual, o que dificultou o diagnóstico definitivo.

Os mecanismos relacionados à resistência ou à suscetibilidade do homem ao Paracoccidioides brasiliensis ainda são desconhecidos. ${ }^{5,7}$ Fatores ligados,principalmente, ao hospedeiro são estado nutricional e socioeconômico, coinfecções, terapêuticas imunossupressoras, alcoolismo e tabagismo. ${ }^{8,9}$ As vias respiratórias e os pulmões são sítios mais comuns de inoculação e localização inicial da doença, variando de 50 a mais de $90 \%$ dos casos. ${ }^{7,9,10}$ Usualmente, sintomas respiratórios são inespecíficos, como febre, dor torácica, tosse, expectoração, hemoptise e dispneia nas formas extensas; e à radiografia de tórax mostram, em 80$90 \%$ dos casos, imagens bilaterais, macro e micronodulares, infiltrativas ou intersticiais, associados à fibrose ou opacificação, geralmente no terço medial e inferior

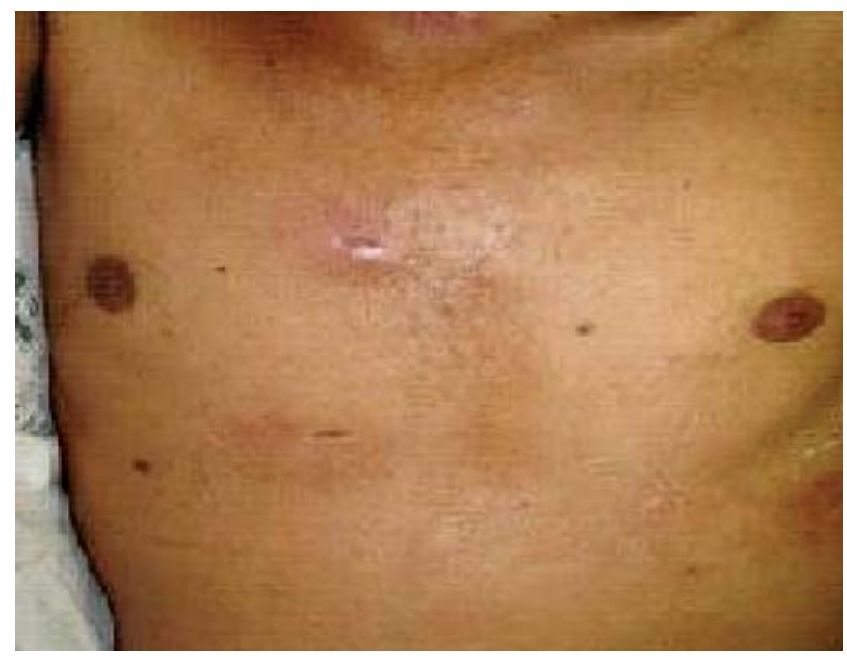

Figura 3: Nódulos eritematosos, drenando secreção purulenta na fúrcula e na região anterior do tórax 


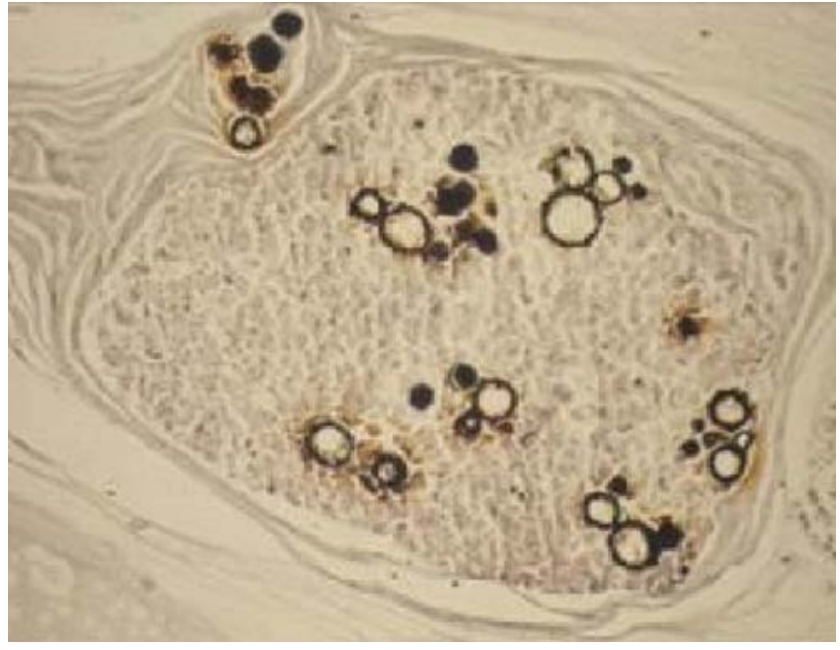

Figura 4: Exame Micológico Direto: Células arredondadas, birrefringentes com múltiplos brotamentos

dos lobos. ${ }^{4,8,7,10}$ Também são encontradas lesões miliárias, pneumônicas e cavitárias. ${ }^{9}$ É rara a ocorrência de ascite e derrame pleural ${ }^{8}$ - o qual foi presenciado desde o início do quadro clínico deste paciente. Isto associada à linfadenopatia, levou à hipótese inicial de tuberculose, a qual foi descartada somente após prova terapêutica, demonstrando a importância da investigação de tuberculose concomitante, o que ocorre em $12 \%$ dos casos.

A PCM pode assumir várias formas clínicas, conforme o órgão afetado.'A frequência, o número e a morfologia das lesões cutâneas são consequência da interação agente/hospedeiro. ${ }^{1} \mathrm{~A}$ incidência de doença, puramente cutânea, é de $12-15 \%$ e tem origem da disseminação hematogênica do fungo $;{ }^{10}$ de lesão contígua preexistente; ou raramente, de inoculação direta. ${ }^{1,8} \mathrm{~A}$ via hematogênica predomina e, em geral, cursa com lesões múltiplas, tais como neste relato. ${ }^{1}$ A lesão cutânea seguindo-se à óssea contígua é evento raro ${ }^{1}$. As alterações cutâneas são polimórficas, variando desde lesões acneiformes a nódulos exsudativos e/ou ulcero-vegetantes. ${ }^{1,5,7}$ À exceção da "estomatite moriforme de Aguiar Pupo", não há quadro cutâneo patognomônico. ${ }^{1}$

Os linfonodos são comprometidos secundariamente ao acometimento cutâneo e/ou visceral, predominando os cervicais ou submandibulares, supraclaviculares e abdominais, simulando tuberculose ganglionar. ${ }^{2,9}$ As adenopatias podem ser regionais ou generalizadas, com flutuação e fistulização.

O comprometimento cutâneo-ganglionar e hepatoesplênico é classicamente evidenciado na forma aguda-subaguda, típico dos jovens e dos intensamente imunossuprimidos. ${ }^{8,9}$ As alterações ósseas são lesões osteolíticas, principalmente, de clavículas, costelas e úmero com tendência à simetria ${ }^{9}$. No caso, o

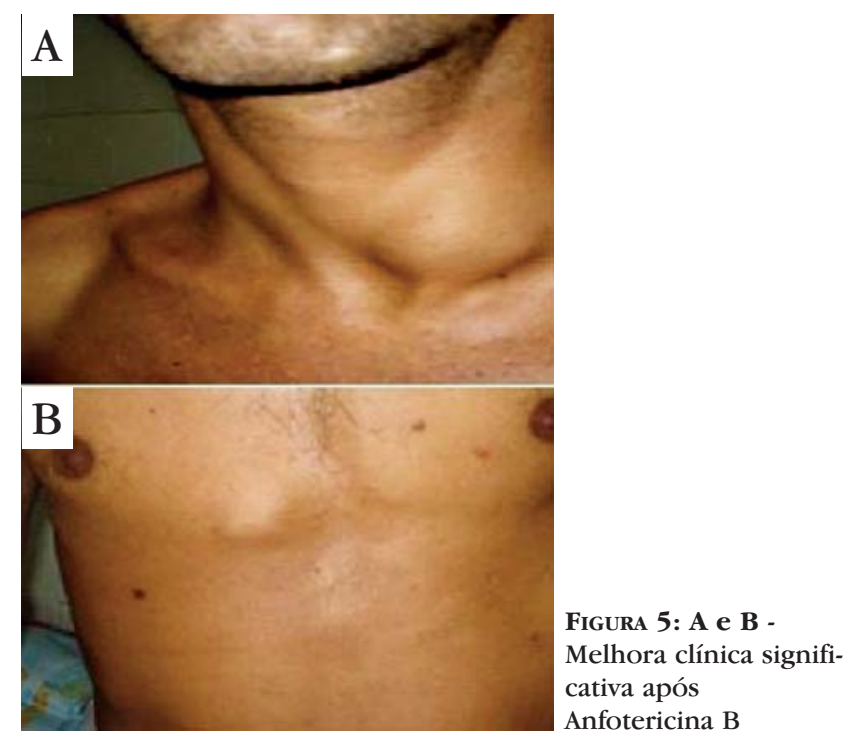

esterno foi afetado, não tendo sido encontrado relatos ou citações deste fato em outros pacientes. O envolvimento ocular é raro, acometendo, principalmente, pálpebras e conjuntiva. ${ }^{2}$ Os tratos gastrointestinal e genitourinário, sistema nervoso e suprarrenais, podem, eventualmente, serem afetados, em especial nos casos mais graves ${ }^{7,9}$, tal como nosso paciente que apresentava proteinúria nefrítica, motivo de sua internação.

A associação de PCM e AIDS é variada, predominando a forma agudo-subaguda, expressando-se por gânglios enfartados cervicais ou generalizados, hepatoesplenomegalia, frequentes lesões cutâneas atípicas, lesões ósseas, tendência à disseminação sistêmica $\mathrm{e}$, eventualmente, associação com a tuberculose. ${ }^{11}$ Portanto, recomenda-se excluir retrovirose em casos multifocais disseminados, além de fatores imunossupressores como uso de drogas ilícitas, os quais foram investigados neste caso.

As drogas eficazes contra a PCM compreendem três grupos: anfotericina B, sulfadiazina e outros compostos sulfanilamídicos; e drogas azólicas com atuação sistêmica. ${ }^{2,79}$ Nos casos graves ou multifocais, a anfotericina B clássica é droga de escolha. ${ }^{8} \mathrm{~A}$ escolha desta foi possibilitada pelo aparato hospitalar, o que permitiu rápida remissão clínica do quadro grave e arrastado deste caso.

No Brasil, deve-se considerar a PCM, principalmente, nos homens expostos ocupacional ou não às atividades rurais; ou oriundos de zonas endêmicas. A abordagem deve ser individualizada e multidisciplinar, já que a clínica é diversa e representa um desafio tanto no diagnóstico, similar a este caso, o qual foi diagnosticado com atraso em mais de um ano; assim como no tratamento de casos disseminados. 


\section{REFERÊNCIAS}

1. Marques SA, Cortez DB, Lastória JC, Camargo RMP, Marques MEA Paracoccidioidomicose: freqüência, morfologia e patogênese de lesões tegumentares. An Bras Dermatol. 2007;82:411-7.

2. Gervini RL, Lecompte SM, Ruthner FG, Vettorato G, Biasi TB, Kronbauer FL. Paracoccidioidomicose da região ocular: relato de dois casos e revisão de literatura. An Bras Dermatol. 2004:79:69-78.

3. Verli FD, Marinho AS, Souza SC, Figueiredo MAS, Yurgel LS. Perfil clínicoepidemiológico dos pacientes portadores de paracoccidioidomicose no Serviço de Estomatologia do Hospital São Lucas da Pontifícia Universidade Católica do Rio Grande do Sul. Revista da Sociedade Brasileira de Medicina Tropical. 2005:38:234-237.

4. Palmeiro M, Cherubini K, Yurgel LS. Paracoccidioidomicose: Revisão da Literatura. Scientia Medica, Porto Alegre: PUCRS. 2005;15:74-278.

5. Zaitz C, Ruiz LRB, Framil VMS. Paracoccidioidomicose: Diagnóstico e Tratamento Manual de Conduta. Jornal da Sociedade Brasileira de Dermatologia. 2006;10:191-196.

6. Valle ACF, Wanke B, Wanke NCF, Peixoto TC, Perez M. Tratamento da Paracoccidioidomicose: Estudo retrospectivo de 500 casos - I. Análise clínica, laboratorial e epidemiológica. An Bras Dermatol. 1992;67:251-254

7. Ramos-e-Silva M. Micoses Profundas. Dermatologia Atual. 2000;6:6-13.

8. Marques SA, Camargo RMP, Marques MEA. Caso para diagnóstico. Paracoccidioidomicose. An Bras Dermatol. 2007;82:579-81.

9. Sampaio SAP, Rivitti EA. Micoses Profundas. In: Sampaio SAP, Rivitti EA, editores. Dermatologia. 3 ed. São Paulo: Artes Médicas; 2007. p.723-33.
10. Achenbach R, Negroni R, Khaski S, Lococo L, Beresñak A, Gai L. Paracoccidioidomycosis: unusual clinical presentation and utility of computerized tomography scanning for diagnosis. Int J Dermatol. 2002:41:881-2.

11. Valle ACF, Wanke B, Wanke NCF, Lima NS, Perez M. Tratamento da Paracoccidioidomicose: Estudo retrospectivo de 500 Casos - II. Avaliação dos resultados terapêuticos com sulfamídicos, anfotericina B, associação sulfametoxazol/trimetoprim, cetoconazol e miconazol. An Bras Dermatol. 1993:68:65-70.

ENDEREÇO PARA CORRESPONDÊNCIA / MAILING ADDRESS:

Livia Lima de Lima

Rua A29 Conjunto Ajuricaba - 293, Planalto

69046310 Manaus - AM, Brasil

Celular: 92 9985-5252

Email: lilimanb@botmail.com

Como citar este artigo/How to cite this article: Pereira PMR,Akel PBM, Lima LL, Kimura EM, Jalkh AP. Paracoccidioidomicose sistêmica multifocal - desafio diagnóstico por manifestação cutânea tardia. An Bras Dermatol. 2011;86(1):149-52. 